\title{
Synthesis of BaTiO3 nanoparticles via hydrothermal method
}

\begin{abstract}
In this work, BaTiO3 nanoparticles were synthesized through hydrothermal method. The powder obtained from the hydrothermal process (as-synthesized powder) was calcined at $1000{ }^{\circ} \mathrm{C}$. The phase formation and morphology of the as-synthesized and calcined powders were studied using X-ray diffraction (XRD), thermogravimetric (TGA) and differential scanning calorimetry (DSC) analyzer, and transmission electron microscope (TEM). The XRD data showed that the as-synthesized powder is partially amorphous. Upon calcining the powder at $1000{ }^{\circ} \mathrm{C}$, highly crystalline $\mathrm{BaTiO} 3$ with tetragonal structure was obtained. As shown by TGA and DSC analysis, the precursor powder was completely transformed into $\mathrm{BaTiO} 3$ at $1000{ }^{\circ} \mathrm{C}$. The presence of $\mathrm{BaCO} 3$ as an impurity phase in the powder is due to the lack of $\mathrm{Ba} 2+/ \mathrm{Ti} 3+/ 4+$. Transmission electron microscope images showed that the particle size of the as-synthesized powder increased after calcination due to crystal growth. In addition, nanocubes with the average size of around $11.66 \mathrm{~nm}$ were obtained as a result of the calcination compared to the ellipsoid like particles of the as-synthesized powder.
\end{abstract}

Keyword: BaTiO3; Hydrothermal synthesis; Nanomaterial; Self-assembly 